\title{
Sunlight-Driven Synthesis of Silver Nanoparticles Using Pomelo Peel Extract and Antibacterial Testing
}

\author{
Vinh Tien Nguyen $(1)$ \\ Faculty of Chemical and Food Technology, Ho Chi Minh City University of Technology and Education, 01 Vo Van Ngan Street, \\ Thu Duc District, Ho Chi Minh City, Vietnam \\ Correspondence should be addressed to Vinh Tien Nguyen; tiennv@hcmute.edu.vn
}

Received 4 June 2020; Revised 21 July 2020; Accepted 21 August 2020; Published 23 September 2020

Guest Editor: Tifeng Jiao

Copyright $(92020$ Vinh Tien Nguyen. This is an open access article distributed under the Creative Commons Attribution License, which permits unrestricted use, distribution, and reproduction in any medium, provided the original work is properly cited.

A green approach, including using phytochemicals in pomelo peel extract (PPE) and direct sunlight, was used to synthesize silver nanoparticles (AgNPs). PPE was prepared by treating pomelo peel with a citric acid solution at $85^{\circ} \mathrm{C}$ for $2 \mathrm{~h}$. PPE was then mixed with $\mathrm{AgNO}_{3}$ and exposed to sunlight to induce the formation of AgNPs. Time-dependent UV-vis spectra of the reaction mixture demonstrated that AgNPs are formed under sunlight irradiation faster than underheating at $90^{\circ} \mathrm{C}$. Characterization techniques, including X-ray diffraction, transmission electron microscopy, and scanning electron microscopy, confirmed the formation of AgNPs with sizes of 20-30 nm. AgNPs synthesized in PPE were more stable toward electrolyte-induced aggregation than those synthesized using the conventional $\mathrm{NaBH}_{4} /$ citrate method. The AgNPs synthesized in PPE showed antibacterial activities comparable to those of $\mathrm{AgNO}_{3}$ at the same silver concentration against four pathogenic bacterial strains. The obtained PPE containing AgNPs, pectin, and other phytochemicals can be utilized further to produce antibacterial and antioxidant films in food packaging and medical applications.

\section{Introduction}

Nowadays, it is well known that silver nanoparticles (AgNPs) are highly toxic to a wide range of microorganisms, including bacteria, fungi, and viruses $[1,2]$. AgNPs can be synthesized using a physical, chemical, or biological approach. The latter is considered green for using renewable sources of chemicals to reduce silver ions into metallic $\mathrm{Ag}$ and cap the AgNPs to maintain their sizes in the nanoscale. The most common source of these renewable chemicals is phytoextracts from different parts of plants. Some examples of aqueous extracts that were utilized to produce AgNPs are those of Polyalthia longifolia leaves [3], Carica papaya fruit [4], Emblica officinalis fruit [5], Citrus limon juice [6], Rosa rugosa leaves [7], Jatropha curcas seeds [8], Capsicum annuum L. leaves [9], and Murraya koenigii leaves [10].

Beside the use of renewable sources of chemicals, another way to make the process of AgNPs production greener is to use energy-efficient techniques, such as microwave, ultrasound, and light irradiations [11]. An interesting technique for the light irradiation approach is to use solar energy from direct sunlight to assist the formation of AgNPs. This technique was successfully applied to produce AgNPs in the presence of plant extracts, including Allium sativum cloves [12], Ocimum sanctum Linn leaves [13], spinach fraction containing and ferredoxin and ferredoxin-NADP ${ }^{+}$ reductase [14], Polyalthia longifolia leaves [3], Zingiber officinale rhizome [15], Pleurotus citrinopileatus [16], and Piper longum catkins [17]. In some cases, sunlight irradiation can induce AgNPs formation without using any intrinsically reducing agents $[18,19]$.

Pomelo (Citrus maxima Merr.) in the citrus family is cultivated mainly in some Asian countries. Pomelo fruit is consumed fresh or as juice, while its peel is discarded as biological waste. However, pomelo peel, which weighs up to $30 \%$ of the total fruit, is considered a good source of valuable phytochemical compounds, such as flavonoids, essential oils, cellulose, and pectin $[20,21]$. The flavonoids in pomelo peel extract can reduce silver ions into metallic Ag particles, and pectin can cap the formed AgNPs to protect them from 
further growth in size. To the best of our knowledge, only few studies used pomelo juice or pomelo peel extract to synthesize AgNPs, and none of these studies utilized sunlight to assist the formation of AgNPs [22-24]. Therefore, we studied the formation of AgNPs in PPE upon exposure to direct sunlight and characterize the synthesized AgNPs, including their stability against electrolyte-induced agglomeration and antibacterial activity against four bacterial strains. The obtained PPE containing AgNPs, pectin, and other phytochemicals can be utilized further to produce antibacterial and antioxidant films in food packaging or medical applications.

\section{Materials and Methods}

2.1. Materials and Reagents. Pomelo peels were collected from a local market (Ho Chi Minh City, Vietnam). Trisodium citrate was purchased from Xilong Scientific Co., Ltd. (China), silver nitrate from Fisher Scientific (USA), sodium hydroxide and sodium borohydride from Sigma-Aldrich (US), trisodium citrate (TSC) from Prolabo Chemicals (France), and ethanol from Chemsol (Vietnam). All the reagents were of at least $99 \%$ pure and used without further purification.

2.2. Preparation of Pomelo Peel Extract (PPE). The green outer skin of pomelo peel was removed, and the white inner layer (with high pectin content) was sliced, cut into small pieces, and sun-dried for 3 days. These dried pieces were then ground into a powder and stored at $4^{\circ} \mathrm{C}$. The procedure for pectin extraction was adapted from a previous study [25]. For each extraction batch, $2 \mathrm{~g}$ of the dried peel powder was mixed thoroughly with $80 \mathrm{~mL}$ of deionized water containing $0.91 \mathrm{~g}$ of citric acid. The mixture was heated to $85^{\circ} \mathrm{C}$ and kept for $120 \mathrm{~min}$ with continuous stirring $(550 \mathrm{rpm})$. Afterward, the mixture was filtered and centrifuged for $15 \mathrm{~min}$ at $14000 \mathrm{rpm}$ to remove the peel particles. The pale yellow supernatant was used immediately for AgNPs synthesis or stored at $4^{\circ} \mathrm{C}$.

To evaluate the pectin content in PPE, the extract was mixed with $95 \%$ ethanol (ethanol:extract of $2: 1 \mathrm{v} / \mathrm{v}$ ), stirred for $10 \mathrm{~min}$, and then left for $1 \mathrm{~h}$. The precipitated pectin gel was filtered, washed 3 times with 95\% ethanol, and finally dried at $70^{\circ} \mathrm{C}$ for $8 \mathrm{~h}$.

\subsection{Sunlight-Induced Synthesis of AgNPs in PPE.} Predetermined volumes of deionized water, PPE, $0.1 \mathrm{M}$ $\mathrm{AgNO}_{3}$ solution, and $0.1 \mathrm{M} \mathrm{NaOH}$ solution (to adjust $\mathrm{pH}$ ) were mixed thoroughly and then put under sunlight for $30 \mathrm{~min}$. UV-vis spectrum of the reaction mixture was recorded from 380 to $800 \mathrm{~nm}$ at $400 \mathrm{~nm} / \mathrm{min}$ every $5 \mathrm{~min}$ using a UV-Vis-NIR-V670 spectrophotometer (JASCO, Japan). In the following text, PPE containing the synthesized AgNPs is denoted as AgNPs/PPE while the PPE containing $\mathrm{AgNO}_{3}$ before sunlight irradiation as $\mathrm{AgNO}_{3} / \mathrm{PPE}$.

2.4. Test of Stability against Electrolyte-Induced Agglomeration. The aggregation stability of the AgNPs/PPE was compared with a control AgNPs solution synthesized by drop-wise adding $2 \mathrm{~mL}$ of $4 \mathrm{mM} \mathrm{NaBH}_{4}$ into $30 \mathrm{~mL}$ of a solution containing $25 \mathrm{mM}$ trisodium citrate and $0.13 \mathrm{mM}$ $\mathrm{AgNO}_{3}$ under stirring [26].

The stability test was carried out by mixing $9 \mathrm{~mL}$ of each AgNPs solution with $1 \mathrm{~mL}$ of $1 \mathrm{M} \mathrm{NaCl}$ [27]. The agglomeration of AgNPs was monitored by regularly recording the absorbance of the mixture for $5 \mathrm{~h}$.

2.5. Characterization of AgNPs. Sizes and shapes of the AgNPs/PPE were evaluated using images recorded by a JEM-1400 transmission electron microscope (JEOL, USA).

To obtain the AgNPs solid for X-ray diffraction measurements, the AgNPs/PPE were coagulated using $0.1 \mathrm{M}$ $\mathrm{ZnSO}_{4}$, centrifuged at $10000 \mathrm{rpm}$, washed three times with deionized water, and dried at $70^{\circ} \mathrm{C}$. The diffraction was measured at 2 theta angles scanned from $35^{\circ}$ to $80^{\circ}$.

2.6. Antibacterial Assay for AgNPs/PPE. The Kirby-Bauer disk diffusion method was used to evaluate the antimicrobial activity of AgNPs/PPE on three Gram-positive (Staphylococcus aureus, Streptococcus pyogenes, and Bacillus subtilis) and one Gram-negative strain (Salmonella typhi). Each bacterial strain was cultured in Luria-Bertani (LB) nutrient medium at $37^{\circ} \mathrm{C}$ for $12 \mathrm{~h}$. Each bacterial suspension was diluted with sterile LB medium to an absorbance of $0.45-0.50$ at $625 \mathrm{~nm}$. The bacterial suspension $(100 \mu \mathrm{L})$ was spread on the dried surface of LB agar in Petri dishes. Each of the following solutions $(20 \mu \mathrm{L})$ was dropped onto a piece of sterilized filter paper: $0.8 \mathrm{mM}$ kanamycin (positive control), PPE (negative control), $0.8 \mathrm{mM} \mathrm{AgNO}_{3}$, and $0.8 \mathrm{mM}$ AgNPs/PPE. The pieces of filter paper loaded with the solutions were put on the surface of the Petri dish with bacteria. After 24 -hour incubation at $37^{\circ} \mathrm{C}$, the diameters of inhibition zones were measured using a Vernier caliper and considered as an indication of antibacterial activity.

The antibacterial test was replicated three times for each bacterial strain. The difference in diameters of the inhibition zones were evaluated using the $t$-test.

\section{Results and Discussion}

3.1. Pectin Content in PPE. In this study, pectin was extracted from pomelo peel using citric acid treatment at $\mathrm{pH} 3.5$ and temperature $85^{\circ} \mathrm{C}$ for $120 \mathrm{~min}$. The extract and the obtained pectin were slightly yellow in color. From $2.00 \mathrm{~g}$ of pomelo peel, $0.23 \mathrm{~g}$ of crude pectin was obtained $(11.5 \%$ yield from pomelo peel). Compared to other studies, this result was lower due to higher $\mathrm{pH}$ and lower temperature of extraction [25]. When using mineral acids such as $\mathrm{HCl}$ or $\mathrm{HNO}_{3}$, the percentages of extracted pectin were approximately 3 times higher than ours [21]. However, citric acid was chosen because of its greenness and its ability to cap AgNPs in the further synthetic step.

3.2. Sunlight-Driven Formation of AgNPs/PPE. UV-vis spectroscopy is a simple yet useful technique to characterize colloids of metallic nanoparticles. It is known that AgNPs 
induce a surface plasmon resonance (SPR) at approximately $410 \mathrm{~nm}$. A lower value of the wavelength at maximum $\left(\lambda_{\max }\right)$ indicates a lower average size of AgNPs, and a higher value of absorbance at $\lambda_{\max }$ indicates a higher concentration of AgNPs [6]. Figure 1 shows the UV-vis spectra and the appearance (inset) of PPE and $\mathrm{AgNO}_{3} / \mathrm{PPE}$ after $30 \mathrm{~min}$ treated with high temperatures and under sunlight. PPE and $\mathrm{AgNO}_{3} / \mathrm{PPE}$ had the same pale yellow color, possibly due to the caramelization of neutral sugars in PPE during the extraction step. Heating the $\mathrm{AgNO}_{3} / \mathrm{PPE}$ mixture to $90^{\circ} \mathrm{C}$ only increased the yellow color intensity and the absorbance, but no new peak appeared. These results indicate that in PPE, which is acidic due to the presence of remaining citric acid, the reduction reaction of silver ions was slow even at $90^{\circ} \mathrm{C}$. This is in agreement with other studies, which reported that the reduction reaction of silver ions by conventional heating is preferred at higher $\mathrm{pH}[28,29]$.

Under sunlight irradiation, the reaction mixture quickly changed from pale yellow to orange-red in less than one minute and gradually turned to deep brown-red for over $3 \mathrm{~h}$. This color change was associated with the development of a peak at $400-434 \mathrm{~nm}$ in the UV-vis spectrum (Figure 2), indicating the formation of AgNPs [28, 30-32].

The influence of electromagnetic irradiation on the formation of AgNPs has been known in several studies $[17,33-35]$. A detailed mechanism was proposed for the action of UV light on the formation of AgNPs in the presence of methoxy polyethylene glycol and silver ions $[36,37]$. However, it should be noted that in many studies, including ours, the reagents were contained in plastic tubes or glass vials that do not transmit UV part of the sunlight $[15,17]$. Therefore, the blue light, which has lower energy than UV light but higher than other regions in the visible spectrum, may play a major role in reducing $\mathrm{Ag}^{+}$ions into metallic $\mathrm{Ag}[16,38]$. A possible mechanism for the reduction of $\mathrm{Ag}^{+}$ions is that the blue light induced tautomerization of the flavonoids in PPE from the enol to the keto form that can release reactive hydrogen atoms responsible for the reduction of $\mathrm{Ag}^{+}$ions [17].

The TEM image (Figure 3(a)) shows that the AgNPs synthesized in PPE were close to spheres with a size range of $13 \pm 6 \mathrm{~nm}$ (mean $\pm \mathrm{SD}, n=29$ ). These low sizes of AgNPs are comparable with those prepared by strong reducing agents such as $\mathrm{NaBH}_{4}$ and $\mathrm{N}_{2} \mathrm{H}_{4}[39,40]$. The SEM image (Figure 3(b)) shows aggregates of AgNPs, which are possibly formed during the sample preparation step for SEM recording. However, one can find in Figure 3(b) that these aggregates are built from AgNPs of approximately $20-30 \mathrm{~nm}$.

The XRD pattern of the synthesized AgNPs/PPE shows four characteristic peaks (Figure 4). These peaks are well matched with those of bulk silver in the face-centered cubic (fcc) structure (JCPDS file No. 04-0783). This result confirmed the ability of PPE o reduce $\mathrm{Ag}^{+}$ions to metallic silver under sunlight.

3.3. Influence of the Reactant Concentrations on the Formation of $A g N P s$. Figure 5 shows that increasing the concentration of $\mathrm{Ag}^{+}$ions from 0.4 to $0.8 \mathrm{mM}$ resulted in the same $\lambda_{\text {max }}$ but higher absorbance, indicating the formation of more AgNPs with almost the same size distribution. However, further increase of $\mathrm{Ag}^{+}$ions to 7.4 and $16.7 \mathrm{mM}$ shifted $\lambda_{\max }$ to the red region and decreased the maximum absorbance, indicating the formation of larger AgNPs [6]. These different characteristics of AgNPs produced under different concentrations of $\mathrm{Ag}^{+}$ions can be explained by the limited amount of reducing and protecting agents in the PPE. When $\mathrm{Ag}^{+}$ion concentration was low, the present reducing and capping agents can effectively reduce $\mathrm{Ag}^{+}$ions and protect AgNPs from agglomeration. When the concentration of $\mathrm{Ag}^{+}$ ions was too high, the limited pectin could not protect all the AgNPs produced, which resulted in their agglomeration into larger and less particles $[28,32]$. This result implies that a careful choice of $\mathrm{Ag}^{+}$concentration is required to synthesize AgNPs with low sizes.

\subsection{Influence of PPE Amount on the Formation of AgNPs.} In our study, PPE played the role of a capping agent that protects AgNPs from agglomeration. Therefore, its amount used in the reaction mixture must be an essential factor in controlling the amount and size of the produced AgNPs. Figure 6 shows that PPE volumes lower than $0.25 \mathrm{~mL}$ did not change the color of the reaction mixture, associating with no peak around $430 \mathrm{~nm}$. This was possibly due to the low reaction rates at low concentrations of reducing agents from PPE. The inset table in Figure 6 shows that increasing the PPE volumes higher than $0.5 \mathrm{~mL}$ resulted in higher maximum absorbance at lower values of $\lambda_{\max }$, indicating the formation of more AgNPs with lower sizes.

3.5. Stability Test of AgNPs. To evaluate the effectiveness of using PPE pectin as a protecting agent for AgNPs, we compared the stability of AgNPs/PPE with that of AgNPs commonly synthesized using $\mathrm{NaBH}_{4}$ as the reducing agent and trisodium citrate as the protecting agent (Figure 7).

In this test, $0.1 \mathrm{M} \mathrm{NaCl}$ was used as a coagulating agent to accelerate the agglomeration of AgNPs [27]. After $120 \mathrm{~min}$ of $\mathrm{NaCl}$ addition, AgNPs protected by citrate ions were significantly agglomerated, as expressed by the reduction in the peak absorbance. At the same time, AgNPs/PPE showed a slight reduction in the peak absorbance, indicating a superior protective effect of pectin against agglomeration of nanoparticles. This is due to the electrosterically stabilizing effect of pectin molecules. They surround the surface of AgNPs to form a polymeric capping layer with negative charges of carboxylate groups. This negative surface charge induces repulsions between AgNPs when they approach each other, thus reducing the chance of their collisions (electrostatic stabilization). Moreover, the polymeric surrounding layer further reduces the chance of their agglomeration upon collisions (steric stabilization). In other studies, polymers (polyvinylpyrrolidone and branched polyethyleneimine) also showed a stabilizing effect better than citrate anions for AgNPs in solutions containing monovalent and divalent coagulants [27, 41]. 


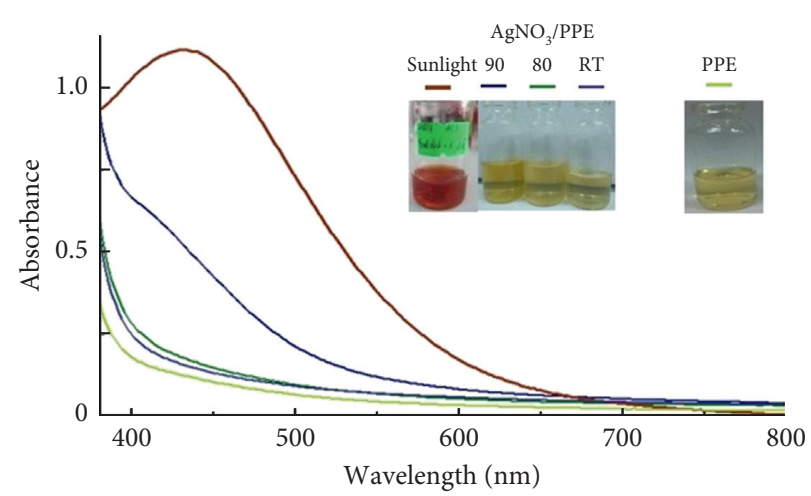

FIgURE 1: UV-vis spectra and appearance of $\mathrm{PPE}$ and $\mathrm{AgNO}_{3} / \mathrm{PPE}$ after 30 min under different reaction conditions: at room temperature (RT), $80^{\circ} \mathrm{C}, 90^{\circ} \mathrm{C}$, and under sunlight.

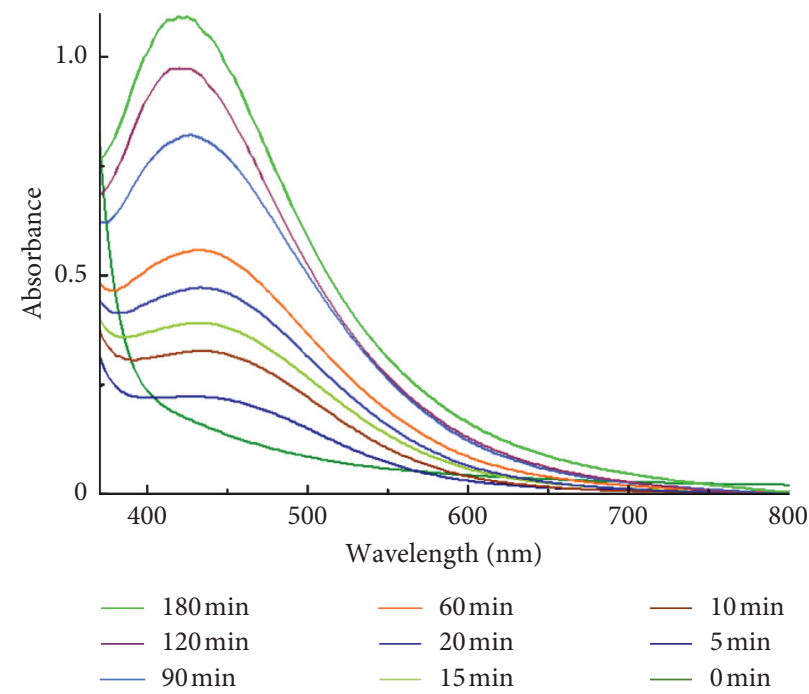

Figure 2: Time-dependent UV-vis spectra of $\mathrm{AgNO}_{3} / \mathrm{PPE}$ under sunlight irradiation.

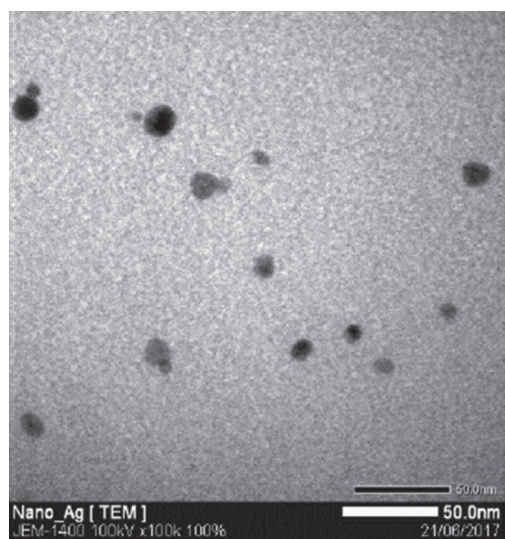

(a)

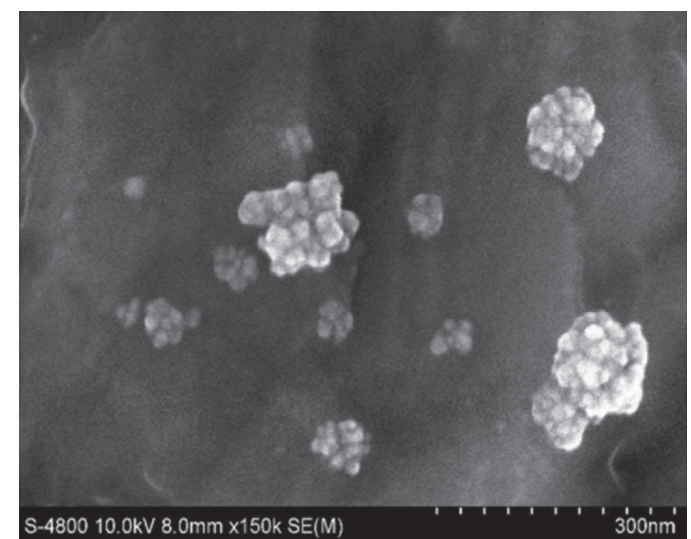

(b)

Figure 3: (a) TEM image of AgNPs/PPE and (b) SEM image of AgNPs clusters after precipitated together with pectin from PPE.

3.6. Antibacterial Activity of AgNPs/PPE. Based on the diameters of the inhibition zones in the antibacterial tests (Figure 8 and Table 1), the order of antibacterial strengths $(p<0.05)$ was kanamycin $>\mathrm{AgNPs}=\mathrm{AgNO}_{3}>\mathrm{PPE} . \quad \mathrm{PPE}$ itself possessed antibacterial effects, possibly due to the presence of citric acid and/or phytochemicals from pomelo 


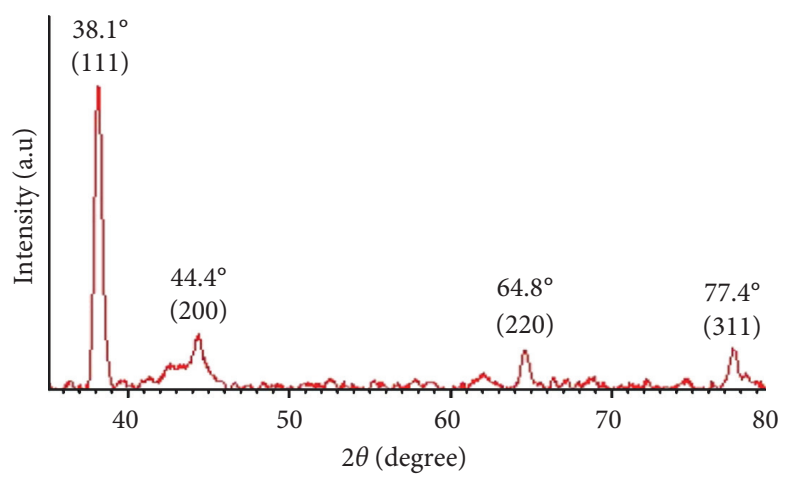

Figure 4: XRD pattern of the AgNPs-pectin powder.

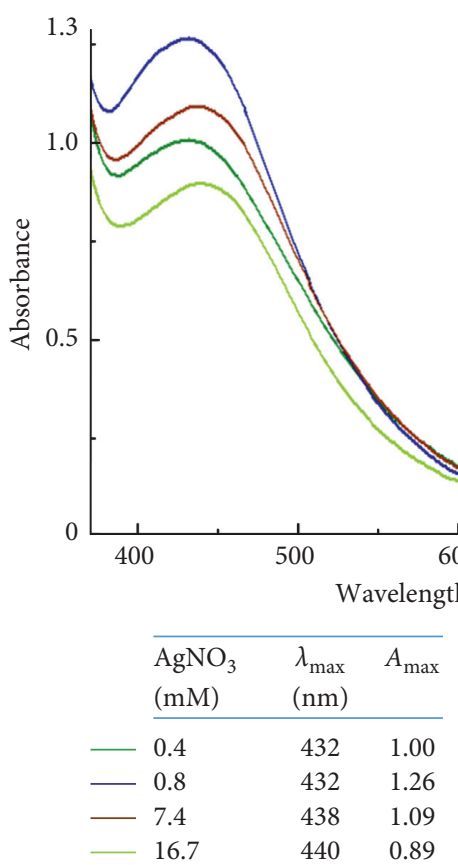

Figure 5: UV-vis spectra of $\mathrm{AgNO}_{3} / \mathrm{PPE}$ with different $\mathrm{Ag}^{+}$concentrations after $30 \mathrm{~min}$ of sunlight irradiation. Inset table: maximum absorbance $\left(A_{\max }\right)$ and $\lambda_{\max }$ of these mixtures.

peel. The higher antibacterial effect of AgNPs/PPE compared to that of PPE indicates that AgNPs in the PPE possesses intrinsic antibacterial activity.

There have been extensive studies on possible antibacterial mechanisms of AgNPs, which revealed that the main mechanism involves the release of $\mathrm{Ag}^{+}$ions from metallic silver [42]. These ions have very high affinities for phosphates, amines, and especially thiols, with which they form a quasi-covalent Ag-S bond (binding energy of approximately $65 \mathrm{kcal} / \mathrm{mol}$ ) [43]. Moreover, silver ions can bridge several thiol groups, forming an irreversible aggregation of the thiol-bearing biological molecules [44]. Therefore, unlike antibiotics that target specific components of the bacterial life cycle, silver ions attack readily any biological molecules
(DNA, membrane-bound peptides, intracellular peptides, or cofactors) bearing target groups [45].

The results above demonstrate that the antibacterial effects of AgNPs/PPE were not different from those of $\mathrm{AgNO}_{3}$ at the same $0.8 \mathrm{mM}$ silver concentration. This seems contradictory common sense that silver ions from $\mathrm{AgNO}_{3}$ should have a higher mobility, and hence a higher antibacterial effect than silver ions released from solid AgNPs. We suggest that the enhanced antibacterial effect of AgNPs/ PPE was due to the presence of citric acid in PPE. Citric acid can release (1) $\mathrm{H}^{+}$ions, which increase the redox potential of dissolved oxygen $\mathrm{E}\left(\mathrm{O}_{2}, \mathrm{H}^{+} / \mathrm{H}_{2} \mathrm{O}\right)$, and (2) citrate ions, which chelate silver ions and thus reduce the redox potential $\mathrm{E}$ $\left(\mathrm{Ag}^{+} / \mathrm{Ag}\right)$. These two combined effects of citric acid could 


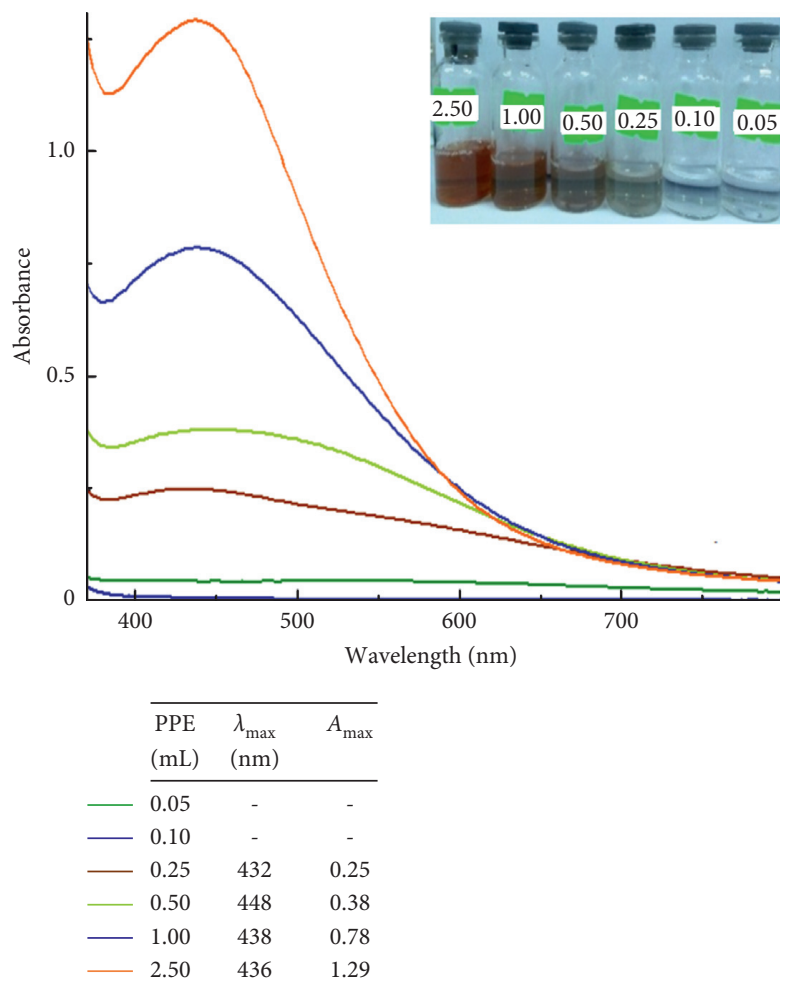

FIgURE 6: Higher amounts of PPE yielded more AgNPs. Inset table: maximum absorbance $\left(A_{\max }\right)$ and $\lambda_{\max }$ of the reaction mixtures.

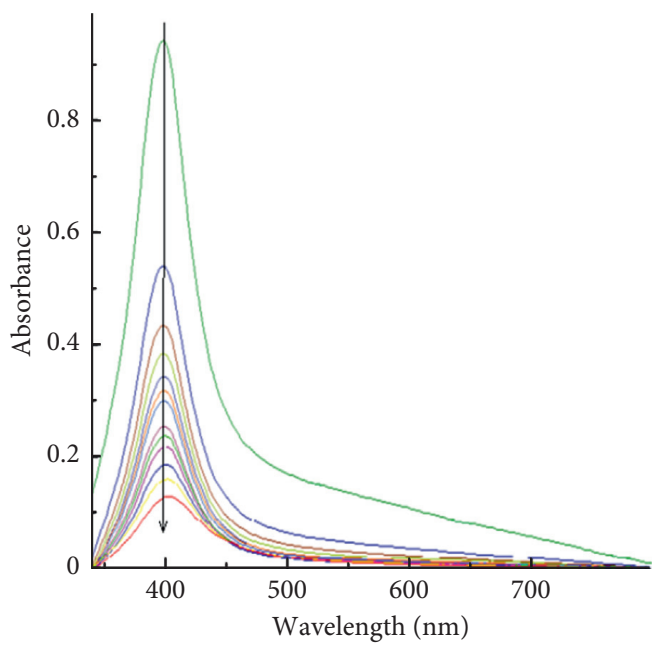

Time (min)

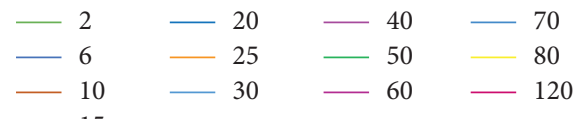

(a)

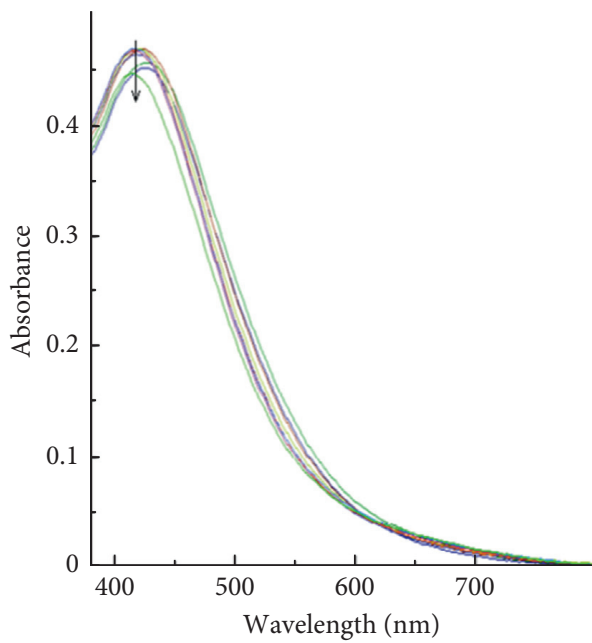

Time (min)

$\begin{array}{lll}-0 & -50 & -120 \\ -5 & -75 & -145 \\ -20 & -95 & -295\end{array}$

(b)

Figure 7: Time-dependent UV-vis spectra of AgNPs solution in the presence of $0.1 \mathrm{M} \mathrm{NaCl}$ (a) AgNPs prepared using $\mathrm{NaBH}_{4}$ and trisodium citrate; (b) AgNPs/PPE. 

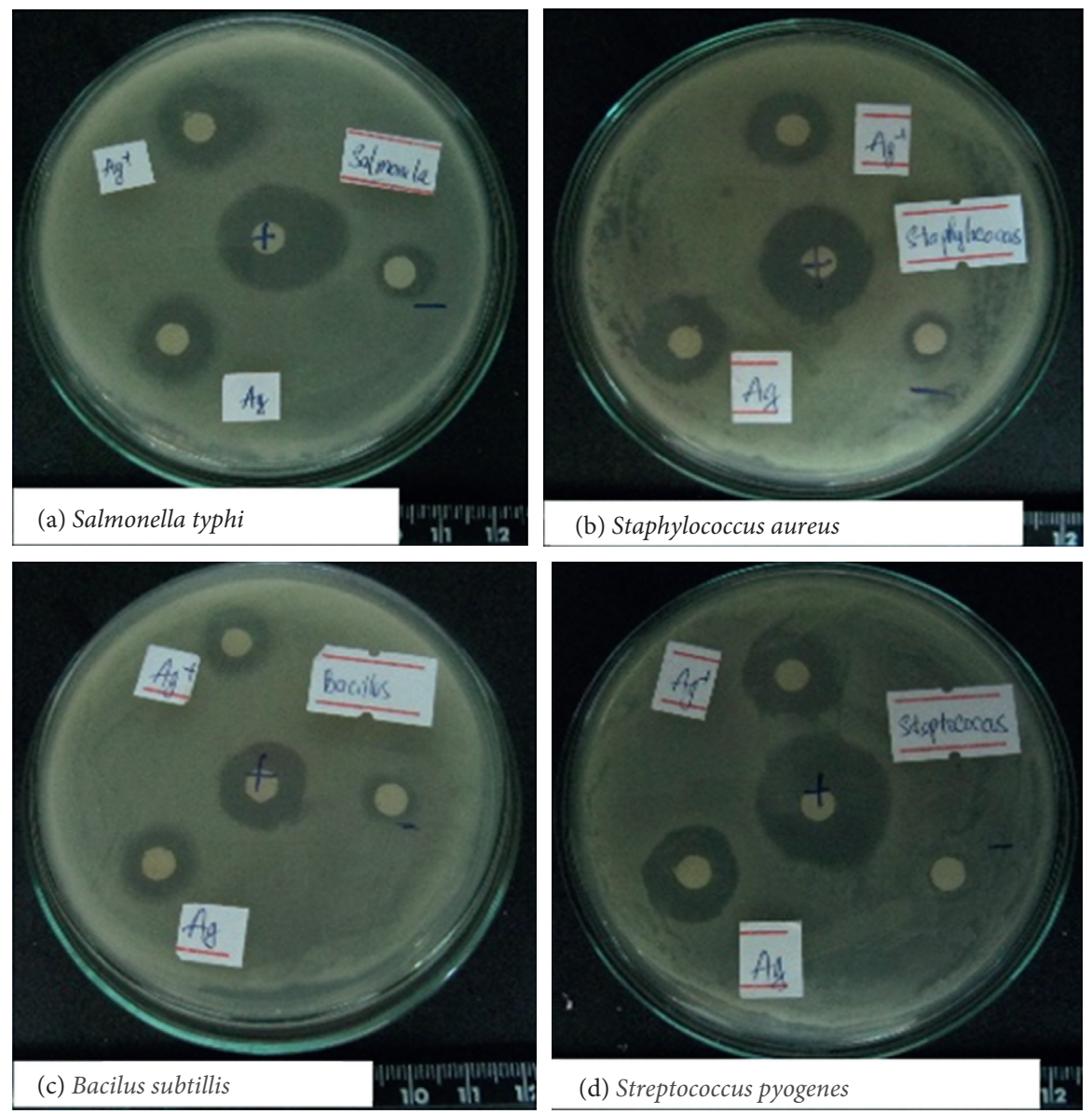

Figure 8: Antibacterial activity of AgNPs in comparison with $\mathrm{AgNO}_{3}$, kanamycin (+), and PPE (-).

TABLE 1: Diameters of inhibition zones $(\mathrm{mm})$ in the antibacterial tests of AgNPs/PPE, PPE, kanamycin, and $\mathrm{AgNO}_{3}$ against four bacterial strains.

\begin{tabular}{|c|c|c|c|c|}
\hline Bacteria & Kanamycin $(+)$ & $\operatorname{PPE}(-)$ & $\mathrm{AgNO}_{3}$ & AgNPs/PPE \\
\hline Salmonella typhi & $17.5 \pm 1.5^{a}$ & $10.4 \pm 0.2^{c}$ & $13.0 \pm 1.9^{b}$ & $13.9 \pm 0.2^{b}$ \\
\hline Staphylococcus aureus & $17.4 \pm 1.2^{a}$ & $8.9 \pm 0.1^{c}$ & $12.4 \pm 1.9^{b}$ & $11.6 \pm 1.1^{b}$ \\
\hline Bacillus subtilis & $13.8 \pm 1.5^{a}$ & $8.5 \pm 0.2^{c}$ & $11.5 \pm 0.7^{b}$ & $11.5 \pm 0.5^{b}$ \\
\hline Streptococcus pyogenes & $17.7 \pm 4.2^{a}$ & $8.3 \pm 0.1^{c}$ & $10.8 \pm 0.8^{b}$ & $11.2 \pm 1.5^{b}$ \\
\hline
\end{tabular}

The results are expressed as mean $\pm \operatorname{SD}(n=3)$. The means in a row with different letters ${ }^{a},{ }^{b}$ or ${ }^{c}$ are significantly different $(p<0.05)$.

enhance the oxidative dissolution of AgNPs into Ag (I) according to the following overall reaction:

$$
\begin{array}{r}
4 \mathrm{Ag}(\mathrm{s})+\mathrm{O}_{2}(\mathrm{aq})+4 \mathrm{H}^{+}(\mathrm{aq})+4 \mathrm{C}_{6} \mathrm{H}_{5} \mathrm{O}_{7}{ }^{3-} \\
\longrightarrow 4 \mathrm{AgC}_{6} \mathrm{H}_{5} \mathrm{O}_{7}{ }^{2-}+2 \mathrm{H}_{2} \mathrm{O}(\mathrm{l})
\end{array}
$$

For AgNPs and $\mathrm{AgNO}_{3}$, the inhibition zone against the Gram-negative $S$. typhi was significantly larger than the other three Gram-positive strains $(p<0.05)$. This higher resistance of Gram-positive strains is consistent with other studies and can be explained by the thick peptidoglycan cell walls that resist the penetration of silver ions into the bacterial cell $[15,46]$.

\section{Conclusions}

In this study, we proved that direct sunlight facilitates the formation of AgNPs in acidic pomelo peel extract (PPE). The flavonoids in PPE are supposed to be the reducing agents for silver ions and pectin as the capping agent for AgNPs. The AgNPs synthesized in PPE demonstrated enhanced stability against agglomeration due to the protective effect of pectin. AgNPs/PPE showed antibacterial effects comparable to those of $\mathrm{AgNO}_{3}$, possibly due to the presence of citric acid and other components in PPE. The obtained PPE containing AgNPs, pectin, and phytochemicals from pomelo peels can be utilized further to produce antibacterial and antioxidant films in food packaging and medical applications. 


\section{Data Availability}

The data used to support the findings of this study are available from the corresponding author upon request.

\section{Conflicts of Interest}

The author declares that there are no conflicts of interest regarding the publication of this paper.

\section{Acknowledgments}

The author gratefully thanks Mr. Minh Thang Nguyen Canh for helpful advices and Ho Chi Minh City University of Technology and Education for financial and facility support in completing this research.

\section{References}

[1] H. H. Lara, E. N. Garza-Treviño, L. Ixtepan-Turrent, and D. K. Singh, "Silver nanoparticles are broad-spectrum bactericidal and virucidal compounds," Journal of Nanobiotechnology, vol. 9, no. 1, p. 30, 2011.

[2] K. S. Siddiqi, A. Husen, and R. A. Rao, "A review on biosynthesis of silver nanoparticles and their biocidal properties," Journal of Nanobiotechnology, vol. 16, no. 1, p. 14, 2018.

[3] V. Kumar, D. Bano, S. Mohan, D. K. Singh, and S. H. Hasan, "Sunlight-induced green synthesis of silver nanoparticles using aqueous leaf extract of Polyalthia longifolia and its antioxidant activity," Materials Letters, vol. 181, pp. 371-377, 2016.

[4] M. Firdaus, S. Andriana, W. Alwi, E. Swistoro, A. Ruyani, and A. Sundaryono, "Green synthesis of silver nanoparticles using Carica papaya fruit extract under sunlight irradiation and their colorimetric detection of mercury ions," Journal of Physics: Conference Series, vol. 817, p. 012029, 2017.

[5] P. S. Hien, T. Kokila, and D. Geetha, "Plant mediated green synthesis and antibacterial activity of silver nanoparticles using Emblica officinalis fruit extract," Spectrochimica Acta Part A: Molecular and Biomolecular Spectroscopy, vol. 142, pp. 339-343, 2015.

[6] T. C. Prathna, N. Chandrasekaran, A. M. Raichur, and A. Mukherjee, "Biomimetic synthesis of silver nanoparticles by Citrus limon (lemon) aqueous extract and theoretical prediction of particle size," Colloids and Surfaces B: Biointerfaces, vol. 82, no. 1, pp. 152-159, 2011.

[7] S. P. Dubey, M. Lahtinen, and M. Sillanpää, "Green synthesis and characterizations of silver and gold nanoparticles using leaf extract of Rosa rugosa," Colloids and Surfaces A: Physicochemical and Engineering Aspects, vol. 364, no. 1-3, pp. 34-41, 2010.

[8] H. Bar, D. K. Bhui, G. P. Sahoo, P. Sarkar, S. Pyne, and A. Misra, "Green synthesis of silver nanoparticles using seed extract of Jatropha curcas," Colloids and Surfaces A: Physicochemical and Engineering Aspects, vol. 348, no. 1-3, pp. 212-216, 2009.

[9] S. Li, Y. Shen, A. Xie et al., "Green synthesis of silver nanoparticles using Capsicum annuum L. extract," Green Chemistry, vol. 9, no. 8, pp. 852-858, 2007.

[10] A. Suganya, K. Murugan, K. Kovendan, P. Mahesh Kumar, and J.-S. Hwang, "Green synthesis of silver nanoparticles using Murraya koenigii leaf extract against Anopheles stephensi and Aedes aegypti," Parasitology Research, vol. 112, no. 4, pp. 1385-1397, 2013.

[11] M. Mohammadlou, H. Maghsoudi, and H. Jafarizadeh-Malmiri, "A review on green silver nanoparticles based on plants: synthesis, potential applications and eco-friendly approach," International Food Research Journal, vol. 23, no. 2, 2016.

[12] L. Rastogi and J. Arunachalam, "Sunlight based irradiation strategy for rapid green synthesis of highly stable silver nanoparticles using aqueous garlic (Allium sativum) extract and their antibacterial potential," Materials Chemistry and Physics, vol. 129, no. 1-2, pp. 558-563, 2011.

[13] G. Gopal, S. Sarkar, R. Ghosh et al., "Sunlight-induced rapid and efficient biogenic synthesis of silver nanoparticles using aqueous leaf extract of Ocimum sanctum Linn. with enhanced antibacterial activity," Organic and Medicinal Chemistry Letters, vol. 4, no. 1, p. 18, 2014.

[14] K. B. A. Ahmed, R. Senthilnathan, S. Megarajan, and V. Anbazhagan, "Sunlight mediated synthesis of silver nanoparticles using redox phytoprotein and their application in catalysis and colorimetric mercury sensing," Journal of Photochemistry and Photobiology B: Biology, vol. 151, pp. 39-45, 2015.

[15] S. Mathew, A. Prakash, and E. K. Radhakrishnan, "Sunlight mediated rapid synthesis of small size range silver nanoparticles using Zingiber officinale rhizome extract and its antibacterial activity analysis," Inorganic and Nano-Metal Chemistry, vol. 48, no. 2, pp. 139-145, 2018.

[16] A. K. Bhardwaj, A. Shukla, S. Maurya et al., "Direct sunlight enabled photo-biochemical synthesis of silver nanoparticles and their bactericidal efficacy: photon energy as key for size and distribution control," Journal of Photochemistry and Photobiology B: Biology, vol. 188, pp. 42-49, 2018.

[17] M. Jayapriya, D. Dhanasekaran, M. Arulmozhi, E. Nandhakumar, N. Senthilkumar, and K. Sureshkumar, "Green synthesis of silver nanoparticles using Piper longum catkin extract irradiated by sunlight: antibacterial and catalytic activity," Research on Chemical Intermediates, vol. 45, no. 6, pp. 3617-3631, 2019.

[18] M. Annadhasan, V. R. SankarBabu, R. Naresh, K. Umamaheswari, and N. Rajendiran, "A sunlight-induced rapid synthesis of silver nanoparticles using sodium salt of N-cholyl amino acids and its antimicrobial applications," Colloids and Surfaces B: Biointerfaces, vol. 96, pp. 14-21, 2012.

[19] G. A. Bhaduri, R. Little, R. B. Khomane et al., "Green synthesis of silver nanoparticles using sunlight," Journal of Photochemistry and Photobiology A: Chemistry, vol. 258, pp. 1-9, 2013.

[20] R. Huang, M. Cao, H. Guo, W. Qi, R. Su, and Z. He, "Enhanced ethanol production from pomelo peel waste by integrated hydrothermal treatment, multienzyme formulation, and fed-batch operation," Journal of Agricultural and Food Chemistry, vol. 62, no. 20, pp. 4643-4651, 2014.

[21] P. Methacanon, J. Krongsin, and C. Gamonpilas, "Pomelo (Citrus maxima) pectin: effects of extraction parameters and its properties," Food Hydrocolloids, vol. 35, pp. 383-391, 2014.

[22] K. A. Ali, R. Yao, W. Wu et al., "Biosynthesis of silver nanoparticle from pomelo (Citrus maxima) and their antibacterial activity against acidovorax oryzae RS-2," Materials Research Express, vol. 7, no. 1, p. 015097, 2020.

[23] N. S. Jalani, W. Michell, W. E. Lin, S. Z. Hanani, U. Hashim, and R. Abdullah, "Biosynthesis of silver nanoparticles using citrus grandis peel extract," Malaysian Journal of Analytical Sciences, vol. 22, no. 4, pp. 676-683, 2018. 
[24] D. Sarvamangala, K. Kondala, U. Murthy, B. N. Rao, G. Sharma, and R. Satyanarayana, "Biogenic synthesis of AGNP's using Pomelo fruit-characterization and antimicrobial activity against Gram +Ve and Gram -Ve bacteria," International Journal of Pharmaceutical Sciences Review and Research, vol. 19, no. 2, pp. 30-35, 2013.

[25] S. Q. Liew, G. C. Ngoh, R. Yusoff, and W. H. Teoh, “Acid and deep eutectic solvent (DES) extraction of pectin from pomelo (Citrus grandis (L.) Osbeck) peels," Biocatalysis and Agricultural Biotechnology, vol. 13, pp. 1-11, 2018.

[26] K. Mavani and M. Shah, "Synthesis of silver nanoparticles by using sodium borohydride as a reducing agent," International Journal of Engineering Research \& Technology, vol. 2, no. 3, pp. 1-5, 2013.

[27] K. A. Huynh and K. L. Chen, "Aggregation kinetics of citrate and polyvinylpyrrolidone coated silver nanoparticles in monovalent and divalent electrolyte solutions," Environmental Science \& Technology, vol. 45, no. 13, pp. 5564-5571, 2011.

[28] N. V. Ivanova, N. N. Trofimova, L. A. Eskova, and V. A. Babkin, "The study of the reaction of Pectin-Ag (0) nanocomposites formation," International Journal of Carbohydrate Chemistry, vol. 2012, Article ID 459410, 9 pages, 2012.

[29] M. Vanaja, G. Gnanajobitha, K. Paulkumar, S. Rajeshkumar, C. Malarkodi, and G. Annadurai, "Phytosynthesis of silver nanoparticles by Cissus quadrangularis: influence of physicochemical factors," Journal of Nanostructure in Chemistry, vol. 3, no. 1, p. 17, 2013.

[30] X. Jiang, C. Chen, W. Chen, and A. Yu, "Role of citric acid in the formation of silver nanoplates through a synergistic reduction approach," Langmuir, vol. 26, no. 6, pp. 4400-4408, 2009.

[31] G. A. Kahrilas, L. M. Wally, S. J. Fredrick, M. Hiskey, A. L. Prieto, and J. E. Owens, "Microwave-assisted green synthesis of silver nanoparticles using orange peel extract," ACS Sustainable Chemistry \& Engineering, vol. 2, no. 3, pp. 367-376, 2014.

[32] M. K. Zahran, H. B. Ahmed, and M. H. El-Rafie, "Facile sizeregulated synthesis of silver nanoparticles using pectin," Carbohydrate Polymers, vol. 111, pp. 971-978, 2014.

[33] M. Bernabò, A. Pucci, F. Galembeck, C. A. d. P. Leite, and G. Ruggeri, "Thermal- and sun-promoted generation of silver nanoparticles embedded into poly(vinyl alcohol) films," Macromolecular Materials and Engineering, vol. 294, no. 4, pp. 256-264, 2009.

[34] A. N. Krklješ, M. T. Marinović-Cincović, Z. M. KacarevicPopovic, and J. M. Nedeljković, "Radiolytic synthesis and characterization of Ag-PVA nanocomposites," European Polymer Journal, vol. 43, no. 6, pp. 2171-2176, 2007.

[35] D. V. Phu, V. T. K. Lang, N. T. Kim Lan et al., "Synthesis and antimicrobial effects of colloidal silver nanoparticles in chitosan by $\gamma$-irradiation," Journal of Experimental Nanoscience, vol. 5, no. 2, pp. 169-179, 2010.

[36] K. Mallick, M. J. Witcomb, and M. S. Scurrell, "Polymer stabilized silver nanoparticles: a photochemical synthesis route," Journal of Materials Science, vol. 39, no. 14, pp. 4459-4463, 2004.

[37] K. Mallick, M. Witcomb, and M. Scurrell, "Silver nanoparticle catalysed redox reaction: an electron relay effect," Materials Chemistry and Physics, vol. 97, no. 2-3, pp. 283-287, 2006.

[38] N. Yang, X.-F. Wei, and W.-H. Li, "Sunlight irradiation induced green synthesis of silver nanoparticles using peach gum polysaccharide and colorimetric sensing of $\mathrm{H}_{2} \mathrm{O}_{2}$," Materials Letters, vol. 154, pp. 21-24, 2015.

[39] S. Agnihotri, S. Mukherji, and S. Mukherji, "Size-controlled silver nanoparticles synthesized over the range $5-100 \mathrm{~nm}$ using the same protocol and their antibacterial efficacy," RSC Advances, vol. 4, no. 8, pp. 3974-3983, 2014.

[40] Z. Khan, S. A. Al-Thabaiti, E. H. El-Mossalamy, and A. Y. Obaid, "Studies on the kinetics of growth of silver nanoparticles in different surfactant solutions," Colloids and Surfaces B: Biointerfaces, vol. 73, no. 2, pp. 284-288, 2009.

[41] A. M. El Badawy, K. G. Scheckel, M. Suidan, and T. Tolaymat, "The impact of stabilization mechanism on the aggregation kinetics of silver nanoparticles," Science of the Total Environment, vol. 429, pp. 325-331, 2012.

[42] Z.-m. Xiu, Q.-b. Zhang, H. L. Puppala, V. L. Colvin, and P. J. J. Alvarez, "Negligible particle-specific antibacterial activity of silver nanoparticles," Nano Letters, vol. 12, no. 8, pp. 4271-4275, 2012.

[43] B. M. Barngrover and C. M. Aikens, "Incremental binding energies of gold(I) and silver(I) thiolate clusters," The Journal of Physical Chemistry A, vol. 115, no. 42, pp. 11818-11823, 2011.

[44] A. N. Milanese, S. D. Gillmor, J. D. Beers, K. M. Beardmore, R. W. Cutts, and B. I. Swanson, "Characterization of chain molecular assemblies in long-chain, layered silver thiolates: a joint infrared spectroscopy and X-ray diffraction study," The Journal of Physical Chemistry B, vol. 103, no. 15, pp. 28502861, 1999.

[45] B. Le Ouay and F. Stellacci, "Antibacterial activity of silver nanoparticles: a surface science insight," Nano Today, vol. 10, no. 3, pp. 339-354, 2015.

[46] P. Pallavicini, C. R. Arciola, F. Bertoglio et al., "Silver nanoparticles synthesized and coated with pectin: an ideal compromise for anti-bacterial and anti-biofilm action combined with wound-healing properties," Journal of Colloid and Interface Science, vol. 498, pp. 271-281, 2017. 